\title{
Endoscopic endonasal approach for sinonasal and anterior skull base malignancies in the elderly
}

\author{
Davide Lepera MD ${ }^{1}$ (D) | Federico Leone MD ${ }^{1} \quad$ Luca Volpi MD ${ }^{1}$ | \\ Maurizio Bignami MD ${ }^{1}$ | Apostolos Karligkiotis MD' (D) I Alessia Lambertoni MD ${ }^{1}$ | \\ Andrea Pistochini MD ${ }^{1}$ | Remo Accorona MD ${ }^{2}$ | Piero Nicolai MD ${ }^{2}$ | \\ Paolo Castelnuovo MD ${ }^{1}$
}

${ }^{1}$ Department of Otorhinolaryngology, Ospedale di Circolo e Fondazione Macchi, University of Insubria, Varese, Italy

${ }^{2}$ Department of Otorhinolaryngology, Spedali Civili, University of Brescia, Brescia, Italy

Correspondence

Davide Lepera, Department of

Otorhinolaryngology, University of

Insubria, Varese, Via Guicciardini 9,

Varese, Italy.

Email: davide.lepera86@gmail.com

\begin{abstract}
Background: The purpose of this study was to report the outcomes of endoscopic transnasal resection for sinonasal and anterior skull-base cancers in elderly patients.

Methods: A retrospective review was performed. The patients were divided into 2 groups, $<70$ years old and $\geq 70$ years old and compared by univariate analysis. Prognostic factors were evaluated with a multivariate analysis. Survival rates were also calculated.

Results: Two hundred three elderly patients and 397 younger patients were enrolled in this study. The elderly patients reported lower survival rates than the younger patients. When melanoma and esthesioneuroblastoma were censored, the diseasespecific survival (DSS) and recurrence-free survival (RFS) were similar. Complication rates were $17.5 \%$ without any statistical significance between the groups. Multivariate analysis revealed that histology, stage, surgical margins, and surgical approaches were independent predictors of survival in elderly patients.

Conclusion: The endoscopic transnasal approach reported low mortality and morbidity rates also in geriatric patients, and age itself is not to be considered as a contraindication.

\section{K E Y W O R D S}

elderly, endoscopic, outcome, sinonasal cancer, skull base
\end{abstract}

\section{1 | INTRODUCTION}

Sinonasal cancers are rare tumors, accounting for 0.5 to 1 new cases $/ 100000$ inhabitants, ${ }^{1}$ with a high variability in terms of histology and biological behavior. Historically, these tumors were related with an extremely poor prognosis due to the local aggressiveness, delayed diagnosis, contiguity with vital structures, high morbidity of skull base surgery, and inability to achieve a free-margin resection. ${ }^{2}$ Craniofacial approaches, introduced in the 1960s by Ketcham et al, ${ }^{3}$ were a major advance in the management of sinonasal cancers, with considerable improvement in the local control of tumors invading the anterior skull base. ${ }^{4}$ Despite the improvement in technical skills and perioperative management, this procedure is still associated with a high rate of complications and mortality ${ }^{5}$ due to the prolonged anesthesia, the use of free tissue transfer, and the significant manipulation of the brain. Elderly patients have a reduced capability to tolerate such important systemic and local insult, with a very poor outcome and a significant increase in postoperative morbidity and mortality. ${ }^{6}$ Recently, the endoscopic endonasal resection techniques in well-selected cases and with appropriate use of 
adjuvant or neoadjuvant treatment have shown encouraging overall survival (OS) and disease-specific survival (DSS) rates with decreased postoperative sequelae. ${ }^{7}$ The possibility to achieve a radical resection of the tumor with a minimal manipulation of the brain, osteotomies, bleeding, and surgical duration is of the utmost importance in the elderly and could be associated with a more favorable outcome in this particular subgroup of patients. The purpose of this study was to present the outcomes of endoscopic transnasal surgery for sinonasal malignant tumors in elderly patients $(\geq 70$ years old); to the best of our knowledge, there are no studies in the literature focusing on this topic.

\section{2 | PATIENTS AND METHODS}

The study foresaw a retrospective review of the patients treated for a sinonasal and/or anterior skull base malignant tumor in 2 tertiary referral centers from June 1995 to January 2016. All the relative clinical, surgical, pathological, and radiological data were retrieved. We retrospectively reviewed data on patient characteristics (sex, symptoms, comorbidities, and previous treatments), tumor features (histology, staging, and site of origin), surgical approaches, and skull base reconstructions, adjuvant and neoadjuvant treatments (chemotherapy and/or radiotherapy), resection margins, and follow-up. Patients with incomplete medical records were excluded. The tumors were retrospectively classified according to the World Health Organization International Histological Classification of Tumors ${ }^{8}$ and were staged according to the Union for International Cancer Control TNM Classification of Malignant Tumors. ${ }^{9}$

The patients enrolled were divided according to their age into 2 groups: $<70$ years old and $\geq 70$ years old. The 2 groups were compared with univariate analysis by using Fisher exact tests or chi-square tests. The variables that we considered were histology, sex, comorbidities, stage of disease, subsites involved, symptoms, adjuvant treatment, intraoperative and postoperative complications, and analysis on surgical margins. The comorbidities considered in our survey were vascular diseases, cardiac diseases, diabetes mellitus, chronic obstructive pulmonary disease, arterial hypertension, and chronic renal failure. Complications were categorized as either major or minor. Minor complications were defined as being of mild severity and self-resolving without the need for further treatment or prolonging the hospital stay; major ones included life-threatening complications requiring medical or surgical treatment, such as cerebrospinal fluid (CSF-1) leaks, meningitis, massive epistaxis, pneumocephalus, pulmonary embolism, sepsis, myocardial infarction and stroke, or complications determining a loss of functions, such as amaurosis and diplopia. We also classified complications into local complications (infection, epistaxis, and hematoma), central nervous system complications (meningitis and pneumocephalus), and systemic complications (myocardial infarction, ictus, and metabolic complications).

All data were collected and processed with a commercially available computer software package (SPSS for Windows, version 19, 2010; SPSS, Chicago, IL). The estimated distribution of the OS, DSS, and recurrence-free survival (RFS) were calculated using the Kaplan-Meier method. Sex, age, histology, surgical approaches, margins of resection, and comorbidities were evaluated by multivariate analysis of survival in the elderly patients, which were carried out using an explorative Cox proportional hazard model $(P$ values $<$ .05 were considered significant).

\section{3 | RESULTS}

Six hundred three patients (603) were enrolled in this survey; 206 patients aged $\geq 70$ years were compared with 397 patients younger than 70 years old.

Patients, tumor features, treatment, and postoperative data, including the univariate analysis are summarized in Tables 1 and 2. A statistically significant difference between the younger and the elderly patients is evident in the distribution of histologies, comorbidities, and adjuvant treatments. Intestinal-type adenocarcinoma (ITAC) was the most represented histological type (in $23.9 \%$ of the younger and $42.2 \%$ of the elderly patients) followed by melanoma in the elderly $(16.5 \%)$ and esthesioneuroblastoma in the younger patients (14.9\%). The univariate analysis showed a significant difference in the histological distribution between the 2 groups $(P$ $=.001)$, mostly related with ITAC, melanoma, and esthesioneuroblastoma. The elderly patients presented with more comorbidities $(59.7 \%$ vs $46.9 \% ; P=.003)$. Younger patients received more frequent adjuvant treatments $(56.7 \%$ vs $46.1 \%$; $P=.014)$. In particular, radiotherapy and chemotherapy were administered to $54.4 \%$ and $10.1 \%$ of the younger group, respectively, and to $37.4 \%$ and $14.1 \%$ of the elderly patients.

The univariate analysis revealed that sex, symptoms, stage of disease, subsite involvement, surgical treatments, and surgical margins had the same distribution between younger and elderly patients. In the younger and elderly patient groups, the men were $65.5 \%$ and $71.4 \%$, respectively, whereas the women were $34.5 \%$ and $28.6 \%$ with a male/ female ratio of $1.9 / 2.5(P=.145)$. Nasal obstruction, epistaxis, and anosmia were the symptoms most reported in both groups $(69.5 \%, 45.3 \%$, and $34.3 \%$ in the younger group, and $65.0 \%, 54.4 \%$, and $27.7 \%$ in the elderly group, respectively; $P=.057)$. The tumors were staged for the younger and elderly patients, respectively, as pT1 in $16.6 \%$ and $17.0 \%$; pT2 in $19.4 \%$ and $21.4 \%$; pT3 in $21.4 \%$ and $23.3 \%$; pT4a in $17.4 \%$ and $11.6 \%$; and pT4b in $25.2 \%$ and $26.7 \%(P=$ $.478)$. Neck lymph nodes $(P=.951)$ and distant metastases 
TA BLE 1 Univariate analysis of patient and tumor characteristics

\begin{tabular}{|c|c|c|c|c|c|c|}
\hline & \multicolumn{3}{|c|}{ No. of patients } & \multicolumn{2}{|c|}{$\%$ of patients } & \multirow[b]{2}{*}{ Univariate } \\
\hline & Younger & Elderly & Total & Younger & Elderly & \\
\hline \multicolumn{7}{|l|}{ Histology } \\
\hline Adenocarcinoma ITAC & 95 & 87 & 182 & 23.93 & 42.23 & a \\
\hline Adenocarcinoma non-ITAC & 27 & 23 & 50 & 6.80 & 11.17 & \\
\hline $\mathrm{SCC}$ & 54 & 22 & 76 & 13.60 & 10.68 & \\
\hline Adenoid cystic carcinoma & 32 & 5 & 37 & 8.06 & 2.43 & \\
\hline Esthesioneuroblastoma & 59 & 5 & 64 & 14.86 & 2.43 & a \\
\hline Melanoma & 22 & 34 & 56 & 5.54 & 16.50 & a \\
\hline Sarcoma & 27 & 5 & 32 & 6.80 & 2.43 & \\
\hline SNUC & 15 & 5 & 20 & 3.78 & 2.43 & \\
\hline SNEC & 11 & 4 & 15 & 2.77 & 1.94 & \\
\hline HPC & 14 & 7 & 21 & 3.53 & 3.40 & \\
\hline Others & 41 & 9 & 50 & 10.33 & 4.37 & a \\
\hline Total & 397 & 206 & 603 & 100 & 100 & $P=.001^{\mathrm{b}}$ \\
\hline \multicolumn{7}{|l|}{ Sex } \\
\hline Male & 260 & 147 & 407 & 65.49 & 71.36 & \\
\hline Female & 137 & 59 & 196 & 34.51 & 28.64 & $P=.145$ \\
\hline \multicolumn{7}{|l|}{ Comorbidities } \\
\hline Yes & 186 & 123 & 309 & 46.85 & 59.71 & \\
\hline No & 211 & 83 & 294 & 53.15 & 40.29 & $P=.003^{\mathrm{b}}$ \\
\hline \multicolumn{7}{|l|}{ pT classification } \\
\hline pT1 & 66 & 35 & 101 & 16.62 & 16.99 & \\
\hline pT2 & 77 & 44 & 121 & 19.40 & 21.36 & \\
\hline pT3 & 85 & 48 & 133 & 21.41 & 23.30 & \\
\hline pT4a & 69 & 24 & 93 & 17.38 & 11.65 & \\
\hline pT4b & 100 & 55 & 155 & 25.19 & 26.70 & $P=.478$ \\
\hline \multicolumn{7}{|l|}{$\mathrm{N}$ classification } \\
\hline No & 389 & 202 & 591 & 97.98 & 98.06 & \\
\hline N-positive & 8 & 4 & 12 & 2.02 & 1.94 & $P=.951$ \\
\hline \multicolumn{7}{|l|}{ M classification } \\
\hline M0 & 394 & 201 & 595 & 99.24 & 97.57 & \\
\hline M-positive & 3 & 5 & 8 & 0.76 & 2.43 & $P=.089$ \\
\hline \multicolumn{7}{|l|}{ Subsites } \\
\hline Septum & 132 & 85 & 217 & 33.25 & 41.26 & \\
\hline Inferior turbinate & 49 & 30 & 79 & 12.34 & 14.56 & \\
\hline Ethmoid & 324 & 171 & 495 & 81.61 & 83.01 & \\
\hline Maxillary & 97 & 39 & 136 & 24.43 & 18.93 & \\
\hline Frontal & 44 & 16 & 60 & 11.08 & 7.77 & \\
\hline Sphenoid & 77 & 41 & 118 & 19.40 & 19.90 & \\
\hline Nasopharynx & 32 & 14 & 46 & 8.06 & 6.80 & \\
\hline PPF/pterygoid & 39 & 9 & 48 & 9.82 & 4.37 & \\
\hline Lacrimal pathways & 16 & 6 & 22 & 4.03 & 2.91 & \\
\hline Periorbit & 43 & 19 & 62 & 10.83 & 9.22 & \\
\hline Skull base & 127 & 70 & 197 & 31.99 & 33.98 & \\
\hline Dura & 68 & 42 & 110 & 17.13 & 20.39 & \\
\hline Brain & 9 & 5 & 14 & 2.27 & 2.43 & $P=.338$ \\
\hline
\end{tabular}


TABLE 1 (Continued)

\begin{tabular}{|c|c|c|c|c|c|c|}
\hline & \multicolumn{3}{|c|}{ No. of patients } & \multicolumn{2}{|c|}{$\%$ of patients } & \multirow[b]{2}{*}{ Univariate } \\
\hline & Younger & Elderly & Total & Younger & Elderly & \\
\hline \multicolumn{7}{|l|}{ Symptoms } \\
\hline Asymptomatic & 39 & 16 & 55 & 9.82 & 7.77 & \\
\hline Obstruction & 276 & 134 & 410 & 69.52 & 65.05 & \\
\hline Rhinorrhea & 93 & 37 & 130 & 23.43 & 17.96 & \\
\hline Epistaxis & 180 & 112 & 292 & 45.34 & 54.37 & \\
\hline Anosmia & 136 & 57 & 193 & 34.26 & 27.67 & \\
\hline Headaches & 66 & 22 & 88 & 16.62 & 10.68 & \\
\hline Facial pain & 24 & 14 & 38 & 6.05 & 6.80 & \\
\hline Visual loss & 11 & 1 & 12 & 2.77 & 0.49 & \\
\hline Epiphora & 22 & 16 & 38 & 5.54 & 7.77 & \\
\hline Diplopia & 6 & 8 & 14 & 1.51 & 3.88 & \\
\hline Swelling & 8 & 3 & 11 & 2.02 & 1.46 & $P=.057$ \\
\hline
\end{tabular}

Abbreviations: HPC, hemangiopericytoma; ITAC, intestinal-type adenocarcinoma; PPF, pterygopalatine fossa; SCC, squamous cell carcinoma; SNEC, sinonasal neuroendocrine carcinoma; SNUC, sinonasal undifferentiated carcinoma.

${ }^{a}$ Indicates the most relevant differences.

${ }^{\text {b }}$ Significant $P$ value.

$(P=.089)$ were evident in $2.0 \%$ and $0.8 \%$ of the younger patients, respectively, and in $1.9 \%$ and $2.4 \%$ of the elderly patients. In both groups, the most frequently involved subsites were the ethmoid sinus ( $81.6 \%$ in the younger patients and $83.0 \%$ in the elderly patients) followed by the septum
(33.3\% and $41.3 \%$, respectively), and the skull base (32.0\% and $34.0 \%$, respectively) with no statistical significant differences between the 2 groups $(P=.338)$. In the younger and elderly patient groups, an endoscopic endonasal resection without craniectomy was performed in $41.6 \%$ and $45.1 \%$

TABLE 2 Univariate analysis of treatment and postoperative data

\begin{tabular}{|c|c|c|c|c|c|c|}
\hline & \multicolumn{3}{|c|}{ No. of patients } & \multicolumn{2}{|c|}{$\%$ of patients } & \multirow[b]{2}{*}{ Univariate } \\
\hline & Younger & Elderly & Total & Younger & Elderly & \\
\hline \multicolumn{7}{|l|}{ Surgical treatment } \\
\hline Endoscopic resection without craniectomy & 165 & 93 & 258 & 41.56 & 45.15 & \\
\hline Endoscopic resection with transnasal craniectomy & 178 & 90 & 268 & 44.84 & 43.69 & \\
\hline Combined transcranial-transnasal resection & 54 & 23 & 77 & 13.60 & 11.17 & $P=.583$ \\
\hline \multicolumn{7}{|l|}{ Adjuvant treatment } \\
\hline Total & 225 & 95 & 320 & 56.68 & 46.12 & \\
\hline RT & 216 & 77 & 293 & 54.41 & 37.38 & \\
\hline Chemotherapy & 40 & 29 & 69 & 10.08 & 14.08 & $P=.014^{\mathrm{a}}$ \\
\hline \multicolumn{7}{|l|}{ Complications } \\
\hline Total & 65 & 41 & 106 & 16.37 & 19.90 & $P=.280$ \\
\hline Major & 26 & 19 & 45 & 6.55 & 9.22 & \\
\hline Minor & 39 & 22 & 61 & 9.82 & 10.68 & $P=.668$ \\
\hline $\mathrm{CNS}$ & 27 & 19 & 46 & 6.80 & 9.22 & \\
\hline Systemic & 15 & 8 & 23 & 3.78 & 3.88 & \\
\hline Local & 23 & 14 & 37 & 5.79 & 6.80 & $P=.280$ \\
\hline \multicolumn{7}{|l|}{ Margins } \\
\hline Positives & 42 & 26 & 68 & 10.58 & 12.62 & \\
\hline Negatives & 355 & 180 & 535 & 89.42 & 87.38 & $P=.565$ \\
\hline
\end{tabular}

Abbreviations: CNS, central nervous system; RT, radiotherapy.

${ }^{\text {a }}$ Significant $P$ value. 
A. Overall Survival

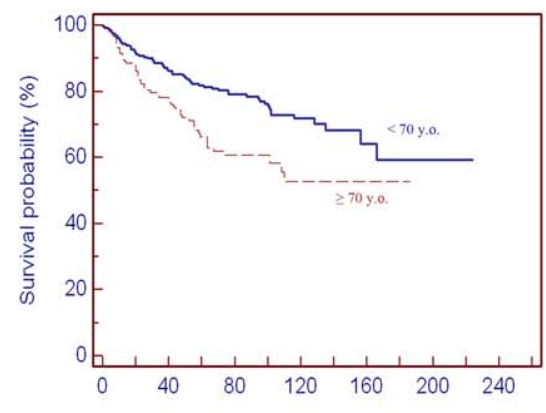

B. Disease Specific Survival

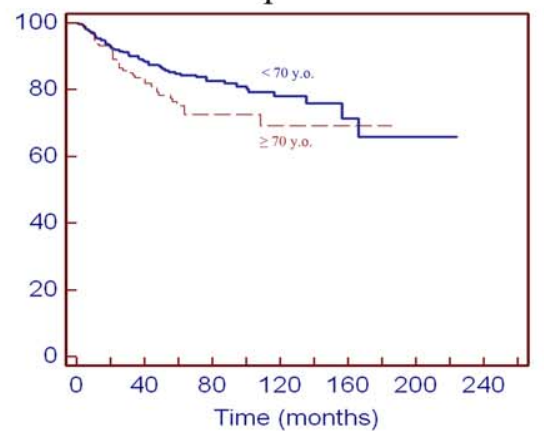

C. Recurrence Free Survival

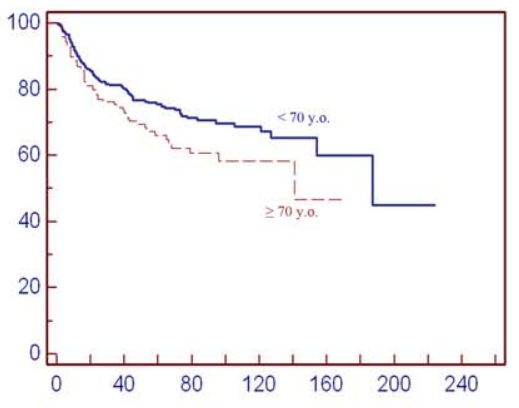

FIG URE 1 A, Overall survival, B, disease-specific survival, and C, recurrence-free survival are illustrated for patients with malignant tumors of paranasal sinuses or anterior skull base stratified by age [Color figure can be viewed at wileyonlinelibrary.com]

cases, respectively, endoscopic resection with transnasal craniectomy in $44.8 \%$ and $43.7 \%$ cases, and a combined transcranial-transnasal resection in $13.6 \%$ and $11.2 \%(P=$ $.583)$.

Complications were reported in $17.5 \%$ of the population enrolled. In the elderly group, the complication rate was $19.9 \%$ and, although this was higher than in the younger group (16.4\%), there was no statistical significant difference $(P=.280)$. Overall, postoperative mortality was $0.33 \%$ (2 cases of blowout of internal carotid artery with exitus in the younger patient group and no cases in the elderly patient group). Positive surgical margins were reported in 68 cases (11.3\%), $10.7 \%$ and $12.6 \%$ in the young and elderly patient groups, respectively $(P=.565)$. Melanoma and adenoid cystic carcinoma have high rates of positive surgical margins due to their biological behavior and local aggressiveness. When melanoma and adenoid cystic carcinoma were censored, positive surgical margins were reported in $8.0 \%$ of the selected population.

The median follow-up was 57 months (range 6-224 months). Five-year and 10-year OS, DSS, and RFS rates for the elderly patients were significantly poorer than for patients aged $<70$ years. The 5 -year OS was $66.3 \% \pm 4.03 \%$ vs $81.9 \% \pm 2.24 \%$, and 10 -year OS was $52.8 \% \pm 5.75 \%$ vs $71.8 \% \pm 3.27 \% ; P=.0003$. The 5 -year DSS was $75.2 \% \pm$
$3.79 \%$ vs $85.0 \% \pm 2.09 \%$, and the 10 -year DSS was $69.3 \%$ $\pm 5.13 \%$ vs $78.3 \% \pm 2.25 \% ; P=.0454$. The 5 -year RFS was $66.2 \% \pm 4.07 \%$ vs $75.4 \% \pm 2.49 \%$, and the 10 -year RFS was $58.4 \% \pm 4.97 \%$ vs $68.8 \% \pm 3.08 \% ; P=.0369)$ Figure 1. When censored for melanoma and esthesioneuroblastoma, only the 5-year and 10-year OS between elderly and younger patients were very close to statistical significance $(P=.054)$, whereas the DSS and RFS were no more statistically significant ( $P=.915$ and .179 , respectively) Figure 2. The 5-year and 10-year OS and DSS of elderly patients with positive surgical margins were comparable with the younger patients and poorer when compared with the elderly patients with negative surgical margins. The survival curves showed moreover that the elderly patients reported a worst survival in local advanced disease (pT3-4) when compared to early disease (pT1-2). The results of the survival curves are summarized in Table 3 .

When elderly patients were stratified according to the presence $(59.7 \%)$ or absence $(40.3 \%)$ of comorbidities, the OS, DSS, and RFS were not statistically different between the 2 subgroups (Figure 3 and Table 3). Elderly patients with comorbidities reported an increased rate of postoperative complications $(20.2 \%)$ compared with elderly patients without comorbidities $(18.6 \%)$. However, no statistical significance was found $(P=.67)$.
A. Overall Survival

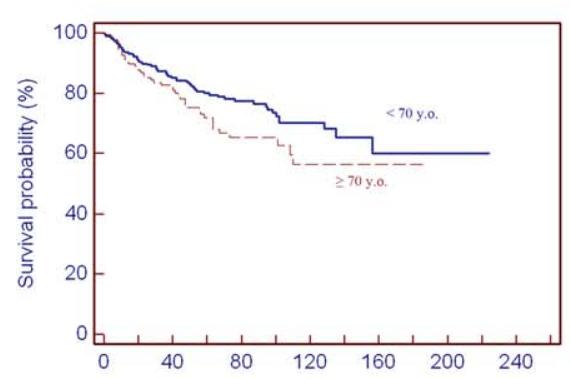

B. Disease Specific Survival

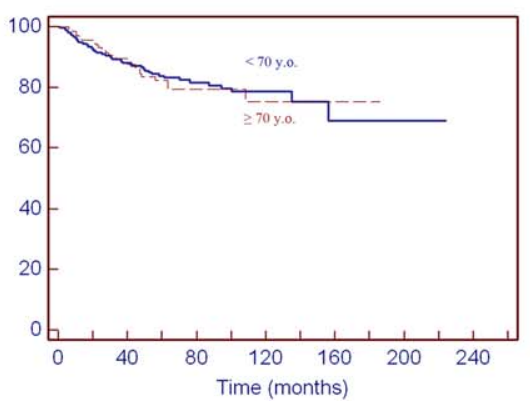

C. Recurrence Free Survival

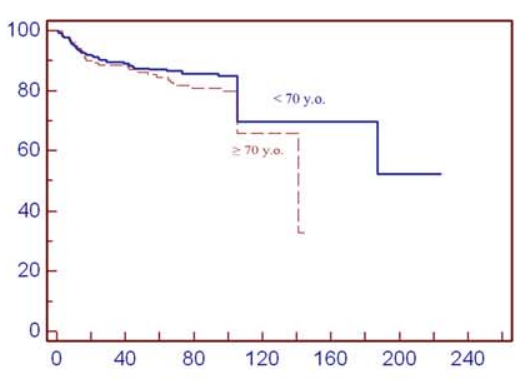

F I G URE 2 A, Overall survival, B, disease-specific survival, and C, recurrence-free survival are illustrated (with melanoma and esthesioneuroblastoma censored) for patients with malignant tumors of paranasal sinuses or anterior skull base stratified by age [Color figure can be viewed at wileyonlinelibrary.com] 
TABLE 3 Survival rates

\begin{tabular}{|c|c|c|c|c|c|}
\hline \multirow{2}{*}{$\begin{array}{l}\text { Survival rates }(\% \pm \mathrm{SE} \%) \\
\text { All patients }\end{array}$} & \multicolumn{2}{|c|}{$5-\mathbf{y}$} & \multicolumn{2}{|c|}{$10-y$} & \multirow[b]{2}{*}{$P$ value } \\
\hline & $<70$ & $\geq 70$ & $<70$ & $\geq 70$ & \\
\hline OS & $81.9 \pm 2.24 \%$ & $66.3 \pm 4.03 \%$ & $71.8 \pm 3.27 \%$ & $52.8 \pm 5.75 \%$ & $.0003^{\mathrm{a}}$ \\
\hline DSS & $85.0 \pm 2.09 \%$ & $75.2 \pm 3.79 \%$ & $78.3 \pm 2.25 \%$ & $69.3 \pm 5.13 \%$ & .0454 \\
\hline RFS & $75.4 \pm 2.49 \%$ & $66.2 \pm 4.07 \%$ & $68.8 \pm 3.08 \%$ & $58.4 \pm 4.97 \%$ & .369 \\
\hline \multicolumn{6}{|l|}{ ONB and melanoma censored } \\
\hline OS & $80.1 \pm 2.59 \%$ & $71.9 \pm 4.16 \%$ & $70.3 \pm 3.64 \%$ & $56.4 \pm 6.34 \%$ & .054 \\
\hline DSS & $83.8 \pm 2.40 \%$ & $82.2 \pm 3.69 \%$ & $78.6 \pm 3.09 \%$ & $75.3 \pm 5.49 \%$ & .915 \\
\hline RFS & $78.1 \pm 2.63 \%$ & $72.2 \pm 4.24 \%$ & $72.6 \pm 3.31 \%$ & $62.9 \pm 5.53 \%$ & .179 \\
\hline \multicolumn{6}{|l|}{ Positive margins in all patients } \\
\hline OS & $70.2 \pm 9.46 \%$ & $26.3 \pm 14.9 \%$ & $52.7 \pm 12.9 \%$ & $26.3 \pm 14.9 \%$ & .1657 \\
\hline DSS & $72.2 \pm 9.52 \%$ & $36.5 \pm 18.9 \%$ & $54.1 \pm 13.2 \%$ & $36.5 \pm 18.9 \%$ & .410 \\
\hline Margins in elderly patients & Positive & Negative & Positive & Negative & \\
\hline OS & $26.3 \pm 14.9 \%$ & $69.4 \pm 4.26 \%$ & $26.3 \pm 14.9 \%$ & $53.3 \pm 6.51 \%$ & $.0051^{\mathrm{a}}$ \\
\hline DSS & $36.5 \pm 18.9 \%$ & $78.0 \pm 3.91 \%$ & $36.5 \pm 18.9 \%$ & $71.1 \pm 5.71 \%$ & $.0070^{\mathrm{a}}$ \\
\hline Elderly patients according to the $\mathrm{pT}$ & pT1-2 & pT3-4 & pT1-2 & pT3-4 & \\
\hline OS & $85.8 \pm 4.75 \%$ & $50.9 \pm 5.99 \%$ & $68.4 \pm 9.31 \%$ & $38.4 \pm 7.99 \%$ & $<.0001^{\mathrm{a}}$ \\
\hline DSS & $96.1 \pm 2.72 \%$ & $59.2 \pm 6.13 \%$ & $93.0 \pm 4.03 \%$ & $48.7 \pm 9.29 \%$ & $<.0001^{\mathrm{a}}$ \\
\hline RFS & $85.4 \pm 4.74 \%$ & $49.4 \pm 5.83 \%$ & $85.4 \pm 4.7 \%$ & $42.3 \pm 8.23 \%$ & $<.0001^{\mathrm{a}}$ \\
\hline Comorbidities in elderly patients & Yes & No & Yes & No & \\
\hline OS & $66.5 \pm 4.78 \%$ & $65.5 \pm 7.49 \%$ & $49.6 \pm 7.16 \%$ & $61.2 \pm 8.16 \%$ & .8267 \\
\hline DSS & $74.9 \pm 4.55 \%$ & $76.2 \pm 6.68 \%$ & $68.3 \pm 6.46 \%$ & $71.1 \pm 7.93 \%$ & .9947 \\
\hline RFS & $66.6 \pm 4.86 \%$ & $64.4 \pm 7.53 \%$ & $63.1 \pm 5.2 \%$ & $44.6 \pm 11.3 \%$ & .2209 \\
\hline
\end{tabular}

Abbreviations: DSS, disease-specific survival; ONB, olfactory neuroblastoma; OS, overall survival; RFS, recurrence-free survival.

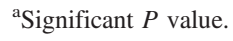

The multivariate analysis in elderly patients reported that pT (T1-2 vs T3-4), histology (esthesioneuroblastoma, adenocarcinoma, melanoma, the carcinoma group, and others], margins (positive vs negative), and surgical approaches (endonasal endoscopic resection with or without craniectomy vs combined transcranial-transnasal resection) were independent predictor factors for the OS and DSS, whereas pT, histology, and surgical margins were independent predictor factors for the RFS (Table 4).

\section{4 | DISCUSSION}

With the increase in life expectancy, the interest of many surgical specialties has moved toward the elderly in terms of extending surgical indications and improving the management of complications. It is known that elderly patients with cancer receive frequently nonstandard treatments. ${ }^{10}$ The fear of severe postoperative complications in this fragile population leads more often to inadequate surgical or nonsurgical management. ${ }^{11}$ Over the past 3 decades, by reducing the invasiveness of the transcranial and transfacial approaches, the endoscopic approach has played an important role in sinonasal and anterior skull base surgery and several authors have published series of elderly patients surgically treated for different sinonasal and skull base pathologies. Jiang and $\mathrm{Hsu}^{12}$ noted that functional endoscopic sinus surgery in the elderly population accounted for $15.6 \%$ of all endoscopic surgeries in their population and reported a slightly increased complication rate as compared to their adult and pediatric group, whereas other authors have concluded that complication rates after functional endoscopic sinus surgery are not related to age. ${ }^{13}$ Emanuelli et al ${ }^{14}$ described a complete closure of the anterior skull base CSF-1 in 20 patients aged $\geq 65$ years old without complications. Zhan et $\mathrm{al}^{15}$ performed a retrospective review of 158 elderly patients (aged 65 years or older) who underwent a purely endoscopic transsphenoidal approach for a pituitary adenoma, comparing them with a series of 155 younger patients with no statistically significant differences in gross tumor removal, visual outcome, relapse, hypopituitarism, diabetes insipidus, CSF-1, or systemic complications. 
A. Overall Survival

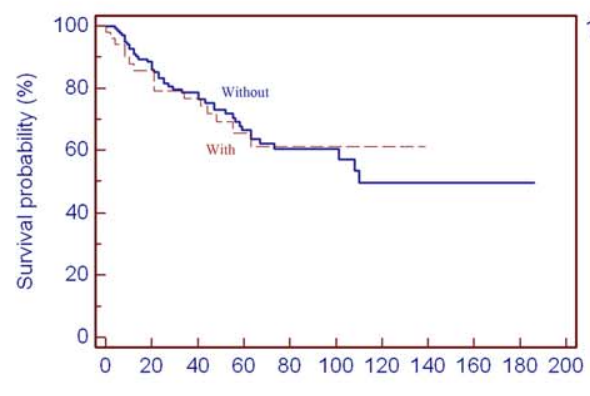

B. Disease Specific Survival

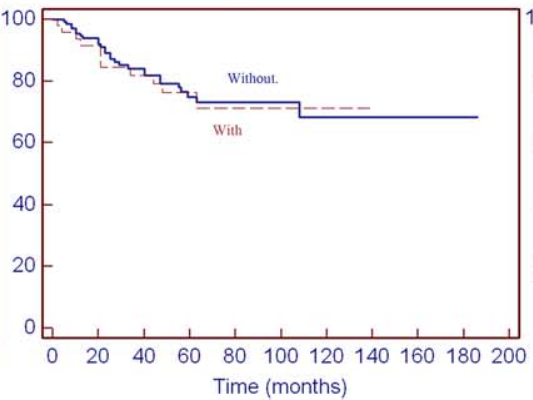

C. Recurrence Free Survival

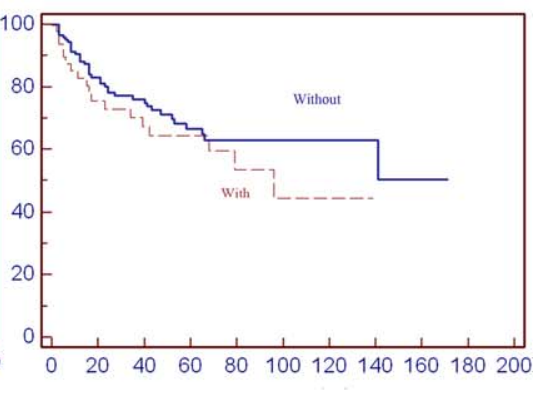

F IG URE 3 A, Overall survival, B, disease-specific survival, and C, recurrence-free survival are illustrated only for elderly patients (aged 70 or more) with malignant tumors of paranasal sinuses or anterior skull base stratified by comorbidities (With: with comorbidities; Without: without comorbidities)

[Color figure can be viewed at wileyonlinelibrary.com]

Both increased experience in the endoscopic management of inflammatory disease, benign tumors, and CSF-1, and the advances in instrumentation, surgical navigation, and skull-base reconstruction, have allowed endoscopic surgery to emerge as a minimally invasive alternative to open approaches during the past decades for sinus and skull base malignancies. This process has been controversial, ${ }^{16-19}$ in particular due to the nonconformity with the oncologic principles of "en bloc" resection. With the transnasal endoscopic approach, free-margin resection is rather achieved through a progressive disassembling of the lesion with a "centripetal" resection. The first step is the debulking of the tumor, followed by a subperiosteal/subperichondrial dissection of the nasoethmoidal complex, including if required the septum and/or contralateral nasoethmoidal complex; the resection could be progressively enlarged superiorly to

TABLE 4 Multivariate analysis in elderly

$\begin{array}{ll}\text { 95\% CI } & \begin{array}{l}\text { Multivariate } \\ \text { analysis, } P \text { values }\end{array}\end{array}$

OS

Sex, $M$ vs $F$

pT1-T2 vs pT3-T4

Histology (esthesioneuroblastoma, adenocarcinoma, carcinoma group, melanoma, and others)

Surgical margins

Endonasal endoscopic resection with or without craniectomy vs combined transcranial-transnasal resection

Medical comorbidities

$\begin{array}{lr}3(1.5-6.3) & .09 \\ 2.02(0.97-4.2) & .038^{\mathrm{a}} \\ 1.6(1.2-2.1) & <.065^{\mathrm{a}} \\ 2.3(1.3-4.5) & .007^{\mathrm{a}} \\ 3.5(1.5-8.1) & .022^{\mathrm{a}}\end{array}$

$0.6(0.3-1.1)$

.12

\section{DSS}

Sex, $M$ vs

pT1-T2 vs pT3-T4

Histology (esthesioneuroblastoma, adenocarcinoma, carcinoma group, melanoma, and others) Surgical margins

Endonasal endoscopic resection with or without craniectomy vs combined transcranial-transnasal resection

Medical comorbidities

$\begin{array}{lr}3(1.5-6.8) & .06 \\ 7.1(1.6-9.2) & .009^{\mathrm{a}} \\ 1.8(1.3-2.5) & <.048^{\mathrm{a}} \\ 2.1(1.3-4.5) & .006^{\mathrm{a}} \\ 3(0.96-9.1) & .048^{\mathrm{a}} \\ & \\ 0.6(0.3-1.5) & .132\end{array}$

\section{RFS}

Sex, M vs F

$\begin{array}{lr}1.9(0.9-5.5) & .13 \\ 5.7(1.9-12.2) & <.016^{\mathrm{a}} \\ 1.5(1.2-2) & .006^{\mathrm{a}} \\ 2.1(0.9-4.2) & .035^{\mathrm{a}} \\ 2.1(0.7-6.6) & .18\end{array}$

pT1-T2 vs pT3-T4

Histology (esthesioneuroblastoma, adenocarcinoma, carcinoma group, melanoma, and others) Surgical margins

$2.1(0.7-6.6)$

.18 
include the ethmoidal roof, the dura mater, the olfactory bulbs, and laterally to include the medial wall of the maxillary sinus with the lacrimal pathways, the papyracea, and the periorbit. ${ }^{20}$ During the last 20 years, endoscopic resection has achieved a general consensus in selected patients progressively clarifying and expanding the indications. ${ }^{21}$ In a recent meta-analysis, Rawal et $\mathrm{al}^{22}$ reported that the 2-year and 5-year OS rates of 759 patients treated with endoscopic endonasal resection for sinonasal malignancies $(85.8 \%$ and $83.5 \%$, respectively) were comparable or even better than the rates reported for open craniofacial resections. Thus, currently, endoscopic and open approaches should not be considered in contrast to each other but should be carefully selected in every case ${ }^{23}$ in order to achieve a radical resection of the tumor. However, the eligibility for craniofacial resection in elderly patients is critical due to the increased perioperative morbidity and mortality ${ }^{6}$ rates encountered. The elderly are usually classified into young-old (65-75 years), old-old (76-85 years), and oldest-old groups ( $>85$ years) ${ }^{24}$ according to the classification adopted by the National Institute on Aging and the National Institutes of Health. However, most clinical studies use as a cutoff the age of 70 years to define elderly patients. ${ }^{25}$ Unfortunately, no universally accepted criteria exist that would facilitate clinical decision making and we adopted 70 years old as our cutoff to obtain results comparable with most studies in literature.

At present, all recommendations for management of elderly patients diagnosed with head and neck cancer are based on retrospective studies or subset analyses of prospective trials. Concerning head and neck cancers, most studies report that extensive surgical treatment (such as laryngectomies, neck dissections, and myocutaneous flap reconstructions) was not related with an increased rate of mortality and was associated with acceptable incidences of complications. ${ }^{26,27}$ Consequently, we can assume that elderly patients with head and neck cancer may be eligible, with proper selection, for extensive surgical treatment. ${ }^{28}$ However, sinonasal and anterior skull base tumors are a particular subgroup of head and neck cancers and should be considered independently; currently, there are no pertinent studies analyzing this subgroup of patients considering the advent of the endoscopic approaches. In literature, there are 3 studies reporting the results of craniofacial surgery in elderly patients, ${ }^{6,29,30}$ whereas not one concerning the endoscopic transnasal approach for sinonasal malignancies could be found.

Our study includes a large sample of patients from 2 Italian tertiary centers with the same policy in terms of diagnostic and therapeutic management of sinonasal cancers. The uniformity of the sample is the strength of this study, although it is a retrospective analysis and it is consequently susceptible to the shortcomings in data collection that are possible in such study designs.
In our analysis, elderly patients showed lower 5-year and 10 -year OS (66.3\% and 52.8\%), DSS (75.2\% and 69.3\%), and RFS (66.2\% and 58.4\%) when compared with patients aged $<70$ (Figure 1 and Table 3). Worst outcomes in elderly patients are demonstrated also in cases of craniofacial surgery in patients aged 70 years or more with 3 -year OS of $53 \%$ and 5 -year OS of $42 \%,{ }^{29,30}$ which are poorer when compared to the present series.

In the present study, no statistically significant differences were found between the young and the elderly patients regarding the TNM classification distribution, also in terms of subsite involvement. The criteria for resectability, which is beyond the intent of our article and is detailed elsewhere, ${ }^{31}$ were applied always regardless of the age of the patients. Because there were no differences in the surgical indications and in subsite involvement, as expected, we found no statistically significant differences between the 2 groups concerning the surgical approaches: endoscopic resection without craniectomy and endoscopic resection with transnasal craniectomy or combined transcranial-transnasal resection. Hence, the compared groups are similar in terms of disease and treatment, thus excluding a potential selection bias in our survey (Tables 1 and 2).

The International Collaborative Study (ICS) group reported that 4 factors were independent predictors of survival outcome of sinonasal malignant tumor ${ }^{32}$ : histology, medical comorbidity, intracranial involvement, and surgical margins. Because of the great variability in the biological behavior, the histology is the main feature for the prognosis of anterior skull base cancers and, in fact, a significant difference in the distribution of the histotypes was evident in our univariate analysis (Tables 1 and 2). Melanoma is a highly aggressive tumor with a poor prognosis (5-year OS 6.5\%$34 \%^{33}$ ) and a higher prevalence in elderly people, ${ }^{34}$ as reported in our data: $16.5 \%$ and $6.0 \%$, respectively. Conversely, younger patients are more affected by esthesioneuroblastoma ( $16.0 \%$ and $2.4 \%$, respectively), which is related with a relatively more favorable prognosis among the sinonasal cancers. ${ }^{35}$ When melanoma and esthesioneuroblastoma were censored, the elderly patients presented worse 5-year and 10 -year OS rates $(71.9 \%$ and $56.4 \%$, respectively) compared to the group of the younger patients $(80.1 \%$ and $70.3 \%$, respectively) with a $P=.05$ (Figure 2 and Table 3). On the other hand, there were no statistically significant differences when we considered the DSS and RFS $(P=.92$ and .18 , respectively). This confirms that the biological behavior and distribution of the different histologies have a prominent role in determining the worst prognosis in the elderly patients.

The multivariate analysis (Table 4) demonstrated that histology, stage of disease, and surgical margins were independent predictors of survival outcome in the elderly patients. Medical comorbidities were not associated with a worse 
outcome, as previously reported, probably due to different factors, such as better perioperative management, more accurate selection of the patients, and the reduced morbidity of the endoscopic approach. Moreover, the Kaplan-Meier test in our analysis failed to reach a statically significant difference between elderly patients with and those without comorbidities (Figure 3 and Table 3), whereas comorbidities have been related with a worse prognosis in craniofacial surgery. ${ }^{29}$

The survival rates in elderly patients reported in our analysis show a dramatic decrease of the OS and DSS for local advanced disease (pT1-2 compared with pT3-4) and positive surgical margins (the data are detailed in Table 3 ). These findings are confirmed by the above-mentioned multivariate analyses.

A study on 1201 patients treated for head and neck cancers (including 87 sinonasal cancers) reports that age did not significantly predict complications and the risk of complications was significantly related to sex, comorbidity, stage, type of surgery, violation of the aerodigestive tract, reconstruction type, neck dissection, and length of intervention; the last one was found to be one of the most important predictors of surgical and nonsurgical complications. ${ }^{27}$ In our survey, we reported complications in $17.5 \%$ of the 603 patients enrolled. Considering the elderly patients, the rate of overall complications was $19.9 \%$, with $10.7 \%$ of minor ones. However, there were no significant differences compared with the younger patients $(16.4 \% ; P=.280)$. Craniofacial resections are generally related with $25 \%-65 \%$ of complications ${ }^{36}$ with a $4.7 \%$ of perioperative mortality. ${ }^{32}$ Considering the elderly patients, the reported complications of craniofacial resections range from $42 \%$ to $64 \%$, and the mortality from $4 \%$ to $17 \% .^{6,29,30}$ Although the endoscopic and craniofacial approaches have different indications and the results presented by the different studies cannot be directly compared, it should be highlighted that the endoscopic approach has encouraging low complications rates in elderly patients.

\section{5 | CONCLUSION}

Advanced age, per se, should not be considered a contraindication to adequate surgical treatment in sinonasal and anterior skull base cancers. Other factors, including comorbidities, disabilities, frailty, and impaired functional status, must be evaluated and represent more relevant criteria than chronological age by itself for decision making. Thus, a comprehensive geriatric assessment along with a multidisciplinary approach is mandatory. Endoscopic endonasal resection is safe and effective also in elderly patients and, when correctly indicated, it should be preferred to open craniofacial resection due to the lower perioperative morbidity and mortality rates and the similar oncologic outcomes. Compared to the younger patients, the elderly patients in our study presented more aggressive histologies, which are factors related with a worse prognosis; when melanoma and esthesioneuroblastoma data were censored, the DSS and RFS proved to be similar in both the young and the elderly patients. Histology, stage of disease, surgical margins, and surgical approaches were independent predictors of survival outcome in the elderly patients.

\section{DICLOSURE}

This work had no specific funding, and there are no conflict of interest disclosures from any authors.

\section{ORCID}

Davide Lepera MD (iD http://orcid.org/0000-0001-7646-2242 Apostolos Karligkiotis MD (D) http://orcid.org/0000-00030129-9908

\section{REFERENCES}

[1] Magnani C, Ciambellotti E, Salvi U, Zanetti R, Comba P. [The incidence of tumors of the nasal cavity and the paranasal sinuses in the district of Biella, 1970-1986]. Acta Otorhinolaryngol Ital. 1989;9(5):511-519.

[2] Frazell EL, Lewis JS. Cancer of the nasal cavity and accessory sinuses. A report of the management of 416 patients. Cancer. 1963;16:1293-1301.

[3] Ketcham AS, Wilkins RH, Vanburen JM, Smith RR. A combined intracranial facial approach to the paranasal sinuses. Am J Surg. 1963;106:698-703.

[4] Lund VJ, Harrison DF. Craniofacial resection for tumors of the nasal cavity and paranasal sinuses. Am J Surg. 1988;156(3 Pt 1):187-190.

[5] Gil Z, Patel SG, Bilsky M, Shah JP, Kraus DH. Complications after craniofacial resection for malignant tumors: are complication trends changing? Otolaryngol Head Neck Surg. 2009;140 (2):218-223.

[6] Ganly I, Gross ND, Patel SG, Bilsky MH, Shah JP, Kraus DH. Outcome of craniofacial resection in patients 70 years of age and older. Head Neck. 2007;29(2):89-94.

[7] Castelnuovo P, Battaglia P, Turri-Zanoni M, et al. Endoscopic endonasal surgery for malignancies of the anterior cranial base. World Neurosurg. 2014;82(6 Suppl):S22-S31.

[8] El-Naggar AK, Chan JKC, Grandis JR, Takata T, Slootweg PJ. WHO Classification of Head and Neck Tumours. International Agency for Research on Cancer 2017.

[9] Brierley JD, Gospodarowicz MK, Wittekind C. TNM Classification of Malignant Tumours. Wiley, 2016.

[10] Sarini J, Fournier C, Lefebvre JL, Bonafos G, Van JT, CocheDequéant B. Head and neck squamous cell carcinoma in elderly patients: a long-term retrospective review of 273 cases. Arch Otolaryngol Head Neck Surg. 2001;127(9):1089-1092.

[11] Datema FR, Ferrier MB, van der Schroeff MP, Baatenburg de Jong RJ. Impact of comorbidity on short-term mortality and 
overall survival of head and neck cancer patients. Head Neck. 2010;32(6):728-736.

[12] Jiang RS, Hsu CY. Endoscopic sinus surgery for the treatment of chronic sinusitis in geriatric patients. Ear Nose Throat J. 2001;80(4):230-232.

[13] Colclasure JC, Gross CW, Kountakis SE. Endoscopic sinus surgery in patients older than sixty. Otolaryngol Head Neck Surg. 2004;131(6):946-949.

[14] Emanuelli E, Milanese L, Rossetto M, et al. The endoscopic endonasal approach for cerebrospinal fluid leak repair in the elderly. Clin Neurol Neurosurg. 2015;132:21-25.

[15] Zhan R, Ma Z, Wang D, Li X. Pure endoscopic endonasal transsphenoidal approach for nonfunctioning pituitary adenomas in the elderly: surgical outcomes and complications in 158 patients. World Neurosurg. 2015;84(6):1572-1578.

[16] Banhiran W, Casiano RR. Endoscopic sinus surgery for benign and malignant nasal and sinus neoplasm. Curr Opin Otolaryngol Head Neck Surg. 2005;13(1):50-54.

[17] Stammberger H, Anderhuber W, Walch C, Papaefthymiou G. Possibilities and limitations of endoscopic management of nasal and paranasal sinus malignancies. Acta Otorhinolaryngol Belg. 1999;53(3):199-205.

[18] Lund V, Howard DJ, Wei WI. Endoscopic resection of malignant tumors of the nose and sinuses. Am J Rhinol. 2007;21(1):89-94.

[19] Samant S, Kruger E. Cancer of the paranasal sinuses. Curr Oncol Rep. 2007;9(2):147-151.

[20] Nicolai P, Castelnuovo P, Bolzoni Villaret A. Endoscopic resection of sinonasal malignancies. Curr Oncol Rep. 2011;13(2):138-144.

[21] Suh JD, Ramakrishnan VR, Chi JJ, Palmer JN, Chiu AG. Outcomes and complications of endoscopic approaches for malignancies of the paranasal sinuses and anterior skull base. Ann Otol Rhinol Laryngol. 2013;122(1):54-59.

[22] Rawal RB, Farzal Z, Federspiel JJ, Sreenath SB, Thorp BD, Zanation AM. Endoscopic resection of sinonasal malignancy: a systematic review and meta-analysis. Otolaryngol Head Neck Surg. 2016;155(3):376-386.

[23] Lepera D, Volpi L, Facco C, et al. Endoscopic treatment of Ewing sarcoma of the sinonasal tract. J Craniofac Surg. 2016;27 (4):1001-1006.

[24] Balducci L. Management of cancer in the elderly. Oncology (Williston Park). 2006;20(2):135-143; discussion 144, 146, 151152.

[25] Argiris A, Li Y, Murphy BA, Langer CJ, Forastiere AA. Outcome of elderly patients with recurrent or metastatic head and neck cancer treated with cisplatin-based chemotherapy. $J$ Clin Oncol. 2004;22(2):262-268.

[26] Spyropoulou GA, Jeng SF, Hsieh CH, Tsimponis A, Shih HS. Microsurgical reconstruction for head and neck cancer in elderly patients. J Reconstr Microsurg. 2014;30(2):91-96.

[27] Peters TT, van Dijk BA, Roodenburg JL, van der Laan BF, Halmos GB. Relation between age, comorbidity, and complications in patients undergoing major surgery for head and neck cancer. Ann Surg Oncol. 2014;21(3):963-970.

[28] Teymoortash A, Ferlito A, Halmos GB. Treatment in elderly patients with head and neck cancer: a challenging dilemma. HNO. 2016;64(4):217-220.

[29] Ganly I, Patel SG, Singh B, et al. Craniofacial resection for malignant tumors involving the skull base in the elderly: an international collaborative study. Cancer. 2011;117(3):563-571.

[30] Hentschel SJ, Nader R, Suki D, Dastgir A, Callender DL, DeMonte F. Craniofacial resections in the elderly: an outcome study. J Neurosurg. 2004;101(6):935-943.

[31] Nicolai P, Battaglia P, Bignami M, et al. Endoscopic surgery for malignant tumors of the sinonasal tract and adjacent skull base: a 10-year experience. Am J Rhinol. 2008;22(3):308-316.

[32] Ganly I, Patel SG, Singh B, et al. Complications of craniofacial resection for malignant tumors of the skull base: report of an International Collaborative Study. Head Neck. 2005;27(6):445451.

[33] Lund VJ, Howard DJ, Harding L, Wei WI. Management options and survival in malignant melanoma of the sinonasal mucosa. Laryngoscope. 1999;109(2 Pt 1):208-211.

[34] Manolidis S, Donald PJ. Malignant mucosal melanoma of the head and neck: review of the literature and report of 14 patients. Cancer. 1997;80(8):1373-1386.

[35] Eden BV, Debo RF, Larner JM, et al. Esthesioneuroblastoma. Long-term outcome and patterns of failure-the University of Virginia experience. Cancer. 1994;73(10):2556-2562.

[36] Gray ST, Lin A, Curry WT, et al. Delayed complications after anterior craniofacial resection of malignant skull base tumors. J Neurol Surg B Skull Base. 2014;75(2):110-116.

How to cite this article: Lepera D, Leone F, Volpi L, et al. Endoscopic endonasal approach for sinonasal and anterior skull base malignancies in the elderly. Head \& Neck. 2018;00:1-10. https://doi.org/10.1002/hed.25045 